Dermatology 2019;235:346-347

DOI: $10.1159 / 000498987$

\section{A Comparative Study of Google Search Trends for Melanoma, Breast Cancer and Prostate Cancer in Finland}

Nicolas Kluger $^{\mathrm{a}}$ Laura J. Bouchard ${ }^{\mathrm{b}}$

a Departments of Dermatology, Allergology and Venereology, Helsinki University Central Hospital, Helsinki, Finland; ${ }^{b}$ Aava Kamppi Medical Centre, Helsinki, Finland

\section{Keywords}

Awareness campaign - Breast cancer - Health promotion . Infodemiology $\cdot$ Medical self-care $\cdot$ Melanoma $\cdot$ Online search interest · Prostate cancer · Skin cancer prevention

\section{Background}

Google Trends [1] is a website that quantifies interest in topics at the population level by analyzing all search queries for a specific term across various regions and languages. It is used as a research tool to analyze the interest of the general population in medical conditions [2]. It has already been applied for melanoma and skin cancers $[3,4]$. Bloom et al. [3] found an increase in the general populations' interest in learning about skin cancer during summer months in the USA. It has been challenged whether the cyclical peak could be related to the skin awareness month campaign that happens every May in the USA [5]. The Euromelanoma campaign takes place also in May in various European countries, such as neighboring Sweden [6].

\section{Methods}

We analyzed here the Finnish population's inquisitiveness regarding melanoma and compared it to breast and prostate cancer. We attained search data using Google Trends extracting data from January 1, 2010, to January 1, 2019, for the search terms melanoma, breast cancer and prostate cancer for Finland. We also conducted a comparative search with various European countries (Belgium, Italy, Portugal and Sweden) for the same period for melanoma. Independent review board approval and patient informed consent were not required. The overall relative search volume indexes (SVIs) were plotted over time to identify periods.
Results

In Finland, searches for melanoma increase strikingly at the beginning of summer during the months of May or June and reach a bottom during winter (data not shown). SVIs also reached a peak mainly during May in Sweden (7 times out of 9 years), Belgium (5 times) and Portugal (5 times), and during June in Finland (5 times) while in Italy inquiries occurred later in July (6 times) (Fig. 1). For breast and prostate cancers, there were overall fewer differences during the year, but peaks were observed mostly in October and November for breast and in November for prostate (data not shown).

\section{Discussion}

Peaks of search for melanoma in Finland occur mainly during summer times as in the USA [3]. Reasons for such an annual peak are still unclear. It can be explained by the arrival of summer, increased sun exposure, lighter clothing and discovery of cutaneous lesions that became more noticeable. Sunscreen advice is a trendier topic during summer time among the media. The role of the awareness campaign in May has been suggested as well [5]. In Finland, the Euromelanoma campaign was experimented for 3 years between 2015 and 2017. Before and after this period, peaks still occurred during the same months. It is likely that Finns are aware of European campaigns abroad. Besides, the World Melanoma Day occurs also in May. Even though the Euromelanoma campaign in Finland cannot explain the cyclical trend for the past 9 years, a rise of SVIs was noted during the first 2 years of the campaign, most likely because of increased media coverage of the campaign. Peaks of SVIs for breast cancer matched the Breast Cancer Awareness Month (pink October, pink ribbon) and for prostate cancer the trendy "Movember" campaign. Our results confirm that awareness campaigns provide a boost at the peak time of interest $[4,7]$.

To conclude, interest of the Finnish population for melanoma increases with the arrival of summer. Melanoma awareness campaigns may act as an additional booster. Because interest reaches a bottom during winter time, it would be of interest that public health initiatives organize a second campaign of information during this period. Scandinavians and Finns tend to take sunny vacations to South Europe or the Far East during winter, increasing the risk of excessive sun exposure and sunburns $[8,9]$.

\section{Key Message}

Google Trends analysis reveals that the interest of the Finnish population for melanoma increases with the arrival of summer. Melanoma awareness campaigns may act as an additional booster.

Disclosure Statement

The authors declare no conflicts of interest.

Funding Sources

The authors declare no funding sources.

\section{KARGER}

(C) 2019 S. Karger AG, Basel 


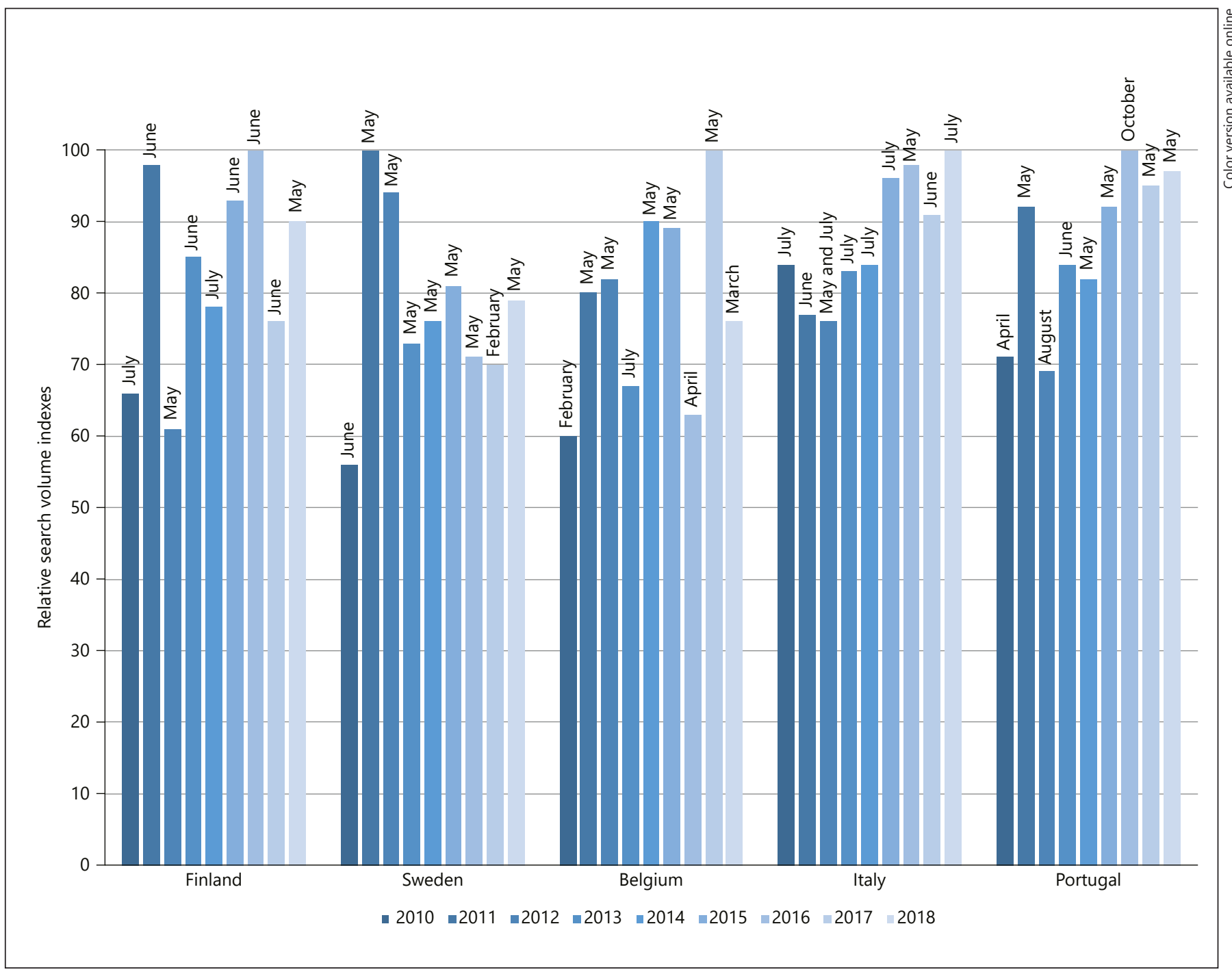

Fig. 1. Relative search volume indexes regarding the term "melanoma" on Google Trends and peak months for Finland, Sweden, Belgium, Italy and Portugal between 2010 and 2018.

\section{References}

1 Google trends. Available from: https://trends.google.com/trends/ (last accessed January 01, 2019)

2 Nuti SV, Wayda B, Ranasinghe I, Wang S, Dreyer RP, Chen SI, et al. The use of google trends in health care research: a systematic review. PLoS One. 2014 Oct;9(10):e109583.

3 Bloom R, Amber KT, Hu S, Kirsner R. Google Search Trends and Skin Cancer: Evaluating the US Population's Interest in Skin Cancer and Its Association With Melanoma Outcomes. JAMA Dermatol. 2015 Aug; 151(8):903-5

4 Hopkins ZH, Secrest AM. An international comparison of Google searches for sunscreen, sunburn, skin cancer, and melanoma: current trends and public health implications. Photodermatol Photoimmunol Photomed. 2018 Sep; https://doi.org/10.1111/phpp.12425.

5 Kantor J. Association of Google Search Volume Index Peaks for Skin Cancer With Skin Cancer Awareness Month. JAMA Dermatol. 2016 Jan; 152(1):113.
6 Paoli J, Danielsson M, Wennberg AM. Results of the 'Euromelanoma Day' screening campaign in Sweden 2008. J Eur Acad Dermatol Venereol. 2009 Nov;23(11):1304-10.

7 Vasconcellos-Silva PR, Carvalho DB, Trajano V, de La Rocque LR, Sawada AC, Juvanhol LL. Using Google Trends Data to Study Public Interest in Breast Cancer Screening in Brazil: Why Not a Pink February? JMIR Public Health Surveill. 2017 Apr;3(2):e17.

8 Køster B, Thorgaard C, Philip A, Clemmensen IH. Vacations to sunny destinations, sunburn, and intention to tan: a cross-sectional study in Denmark, 2007-2009. Scand J Public Health. 2011 Feb;39(1):64-9.

9 Kojo K, Jansen CT, Nybom P, Huurto L, Laihia J, Ilus T, et al. Population exposure to ultraviolet radiation in Finland 1920-1995: exposure trends and a time-series analysis of exposure and cutaneous melanoma incidence. Environ Res. 2006 May;101(1):123-31. 